\title{
Public health matters: why is Latin America struggling in addressing the pandemic?
}

\author{
Adolfo Martinez-Valle ${ }^{1}$ iD
}

Accepted: 7 December 2020 / Published online: 28 January 2021

(c) The Author(s), under exclusive licence to Springer Nature Limited part of Springer Nature 2021

\begin{abstract}
This article examines how Argentina, Brazil, Chile, Colombia, Mexico, and Peru addressed the COVID-19 pandemic and the effectiveness of these policy responses from the date each country declared a sanitary emergency, between middle and late March 2020 to the most recent available measurement on 23 September 2020. To analyze how governments responded to the COVID-19 pandemic in these six Latin American countries, we use an index of government response, created by the University of Oxford. To explore the effects of these governmental mitigation policies on reducing social mobility, we use Google mobility reports. We also analyze how these policies may have influenced COVID-19 mortality rates. Overall, the results showed that both timelier and more stringent implementation of the public policies analyzed to address the COVID-19 pandemic seem to be associated with higher mobility reductions and lower mortality rates. We draw five policy lessons from the way each country implemented these mitigation policies.
\end{abstract}

\section{Key message}

- Timelier and more stringent implementation of these public policies may contribute to a higher mobility reduction in several public spaces and to lower mortality rates.

- The effectiveness of the closure and containment policies in each Latin American country seem to depend on the degree of compliance of their respective populations and to their socioeconomic living conditions.

- Economic and social policies of income support and debt relief provided by governments allowed people to comply with closure and containment policies.

- Health systems should maintain high levels of policy stringency together with effective surveillance through testing policy and contact tracing.

Keywords Latin America · Health systems · Public policies · COVID-19 · Public health policy lessons

Supplementary information The online version of this article (https://doi.org/10.1057/s41271-02000269-4) contains supplementary material, which is available to authorized users.

Extended author information available on the last page of the article 


\section{Introduction}

Most Latin American countries are struggling to address the COVID-19 pandemic. Strong empirical evidence recently begins to show what works best for addressing the pandemic $[1,2]$. This recent literature focuses on experiences in East Asia, Europe, and the United States [3, 4], including several studies based on previous epidemic experiences [5-7]. Latin America, despite becoming the hardest region struck by the pandemic, has been much less studied [8-12]. Further research is needed to better understand how our policymakers and institutions are dealing with this pandemic and its consequences [11]. More specifically, comparative research between countries will be particularly helpful in assessing the effects of different policy strategies to address this unprecedented global health challenge [13, 14].

This article examines how six Latin American health systems addressed the pandemic and the effectiveness of these policy responses. A health system is defined here as a set of organizations and people, as well as the actions they take, whose main purpose is to promote, restore, and maintain health [15]. This definition involves not only the government, which must lead and coordinate the actions in question. It also requires shared responsibility of the entire population and of the organizations and institutions whose actions influence health-families that protect themselves at home, the student population that learns at a distance, the media that distribute information, the companies that temporarily close their doors, and the medical institutions that handle the most delicate cases.

This article first describes the initial situation of the pandemic in each Latin American country and how the government responded. Then it analyzes when and how strictly governments enforced mitigation policies and the effects produced in reducing social mobility of the population in various public spaces. Third, it analyzes COVID-19-related weekly mortality trends to explore differential effects of public policies on this health indicator. Finally, it draws policy lessons from the way each country implemented these mitigation policies.

\section{Methodology}

We performed a comparative policy analysis on how six Latin American health systems addressed the pandemic and the effectiveness of these policy responses from the date each country declared a sanitary emergency between middle and late March to the most recent available measurement on 23 September 2020. We selected Argentina, Brazil, Chile, Colombia, Mexico, and Peru because they had the data necessary to carry out the analysis, represented the most populated nations on the continent, had similar overall population health status, measured as life expectancy at birth, and confirmed their first COVID-19-infected case between late February and early March. To better assess how each country responded to the pandemic, we also considered how well prepared were their health systems, comparing several key indicators from the most recently available Pan American Health Organization (PAHO) report [16]. We used public health expenditures as percentage of 
Gross Domestic Product (GDP) to compare the overall financial resources allocated to public health. Higher percentages of out-of-pocket expenditures allow comparing which health systems are not satisfying health care needs, especially drugs. The Global Health Security Index (GHSI) is an indicator that allows comparison of how well prepared was each health system before the pandemic started in terms of public health infrastructure, epidemiological surveillance, and capacity to deliver appropriate medical care, among other characteristics [17]. We employed life expectancy at birth to measure overall health system performance and maternal mortality rates per hundred thousand population to compare health care performance. Finally, we included the percentage of the populations living with diabetes and aged over 65; both have been identified as two of the most important COVID-19-related mortality risk factors.

We employed several socioeconomic indicators from the same PAHO report [16] to consider how each country could influence the effectiveness of the public policies implemented to address the pandemic. We used US Purchasing Power Parity dollars (PPP) per capita to compare the capacity of the economies to face the pandemic and the GINI index to compare income inequality. To compare what percentages of their total populations were more vulnerable to the effects of the pandemic and less likely to comply with the mitigation and control policies, we used percentages of poverty, extreme poverty, and population with vulnerable jobs [18]. Finally, we used years of schooling for each country to explore whether education would influence compliance with the public policies implemented.

To analyze how governments responded to the COVID-19 pandemic in these six Latin American countries, we use an overall index of government response and two of its disaggregated indices, created by the University of Oxford, which allows comparison of how public policies are implemented to mitigate the effects of coronavirus worldwide [19]. The COVID-19 Government Response Index monitors thirteen indicators to compare the stringency of policy responses to the coronavirus around the world. The first eight indicators measure closure policies in schools, workplaces, public transportation, and public event cancelations, stay at home restrictions, restrictions on domestic travel, and international travel controls. Two economic indicators measure income support for people who lose their jobs or cannot work and debt relief for those who do not have capacity to pay for loans. Finally, three health policy indicators measure if there are public information campaigns, how are testing policies targeted, and how comprehensively contact tracing is implemented.

This overall government response index is a simple additive score of the 13 indicators measured on an ordinal scale, rescaled to vary from 0 to 100 . The ordinal scales measure the strictness of the public policy. For example, if the workplace closing policy required closing for every activity, except the essential ones, such as health care or grocery shops it is classified with a 3, required closing for some sectors is a 2, and when closing is only recommended and not required, it is a 1 and no policy a 0 . This overall government index can be disaggregated into indices with fewer indicators. The index of mitigation and health policies, which includes 11 indicators, the 8 mitigation public policies, and the 3 health policy indicators, measures how strictly these policies are implemented without considering the economic policies. The index of economic support only includes the 2 economic variables. 
We analyze each index separately to better assess its effects on social mobility and health.

To explore the effects of these public policies on reducing social mobility, we use Google mobility reports [20]. These provide aggregated and anonymous data that allow one to plot movement trends over time in different region and settings from users who have the location history activated on their mobile phones. Public mobility spaces range from recreational areas such as parks and squares; retail and recreational spaces such as restaurants, cafés, and shopping centers, to places considered more essential for buying groceries in supermarkets and drugs in pharmacies; means of transportation through transit stations such as subways and buses; and workplaces where people need to earn a living [20]. The dataset consists of daily regional percentages of change from the median value of the corresponding weekday during the 5-week baseline period ( 3 January to 6 February 2020). In this study, we focused on the period from 12 March to 23 September 2020 with days as a time unit. For each country, we considered days starting from when the country declared a sanitary emergency.

We then analyzed how these policies may have influenced COVID-19 mortality rates. We calculated these rates using the number of new weekly deaths related to COVID-19 obtained from the Johns Hopkins University COVID-19 dashboard [21], divided by the number of people in each country, obtained from the Panamerican Health Organization Basic Health Indicators data base [16]. Even though underreporting of COVID-19-related deaths has been a characteristic of all the Latin American health systems analyzed, they are the most reliable health outcome indicators available for assessing the evolution of the pandemic (excess deaths were not available for every country analyzed) because they allow for cross-country analysis and do not depend on the even higher underreported numbers of positive COVID-19 cases in most Latin American countries.

\section{Results}

Government responses to the COVID-19 pandemic in the region have been diverse. Argentina and Colombia imposed total closures on 20 and 24 March 2020, respectively. Peru did the same earlier on 15 March 2020, while the remaining three countries made partial closures around 15 March 2020. Brazil and Mexico were the last two of these countries to declare health emergencies. Brazil declared it on 19 March 2020; Mexico did so on 23 March 2020.

Table 1 summarizes the dates of detection of the first cases, of the emergency sanitary declaration, as well as dates and types of social distancing measures taken to reduce the risk of contagion and mitigate the effects of the pandemic. Argentina, Colombia, and Peru implemented total closures, while Chile, Brazil, and Mexico implemented partial closures. Argentina, Colombia, Perú, and Chile declared sanitary emergencies less than 10 days after each detected its first COVID-19 case. In contrast, Brazil declared sanitary emergency nearly a month after the first case was detected and Mexico took little more than a month. 
Table 1 Key dates for decision making, health systems, and socioeconomic characteristics in the six selected Latin American countries (adapted from [17, 18])

\begin{tabular}{lllllll}
\hline Characteristics & \multicolumn{2}{l}{ Country } & & & & \\
\cline { 2 - 7 } & Argentina & Brasil & Chile & Colombia & México & Peru \\
\hline Key dates for decision making & & & & & & \\
First detected case & $3 \mathrm{Mar}$ & $26 \mathrm{Feb}$ & $3 \mathrm{Mar}$ & $6 \mathrm{Mar}$ & $28 \mathrm{Feb}$ & $6 \mathrm{Mar}$ \\
Sanitary emergency & $12 \mathrm{Mar}$ & $19 \mathrm{Mar}$ & $15 \mathrm{Mar}$ & $12 \mathrm{Mar}$ & $30 \mathrm{Mar}$ & $15 \mathrm{Mar}$ \\
First measures taken & $14 \mathrm{Mar}$ & $19 \mathrm{Mar}$ & $15 \mathrm{Mar}$ & $12 \mathrm{Mar}$ & $23 \mathrm{Mar}$ & $15 \mathrm{Mar}$ \\
Type of closure & Total & Partial & Partial & Total & Partial & Total \\
Health systems characteristics & & & & & & \\
Public health expenditures (\%) & 5.6 & 3.9 & 5 & 3.7 & 2.9 & 3.3 \\
OOP* expenditures (\%) & 15.8 & 27.4 & 34.8 & 20.2 & 40.4 & 28.3 \\
GHSI** & 58.6 & 59.7 & 58.3 & 44.2 & 57.6 & 49.2 \\
Life expectancy at birth & 76.7 & 75.9 & 80.2 & 77.3 & 75.1 & 76.7 \\
Maternal mortality rate per 100, 000 live & 28.7 & 64.5 & 17.3 & 51 & 34 & 70 \\
$\quad$ births & & & & & & \\
Diabetes prevalence (\%) & 9.7 & 8.2 & 10.5 & 8.5 & 11.2 & 7.6 \\
Population over 65 (\%) & 11 & 9 & 12 & 9 & 7 & 8 \\
Socioeconomic characteristics & & & & & & \\
PPP*** per capita & 19,820 & 15,820 & 24,250 & 14,490 & 19,440 & 13,810 \\
Poverty (\%) & 24.4 & 19.4 & 10.7 & 29.9 & 41.5 & 45.1 \\
Extreme poverty (\%) & 3.6 & 3.6 & 1.4 & 10.8 & 10.6 & 16.3 \\
GINI & 40.6 & 53.3 & 46.6 & 44 & 43.4 & 44.7 \\
Population with vulnerable job (\%) & 22 & 28 & 23 & 47 & 27 & 50 \\
Years of schooling & 11.4 & 7.6 & 10.3 & 8.3 & 8.6 & 9.2 \\
\hline
\end{tabular}

*OOP: Out-of-Pocket, **GHSI: Global Health Security Index, ***PPP: Purchasing Power Parity

Overall, the health systems of Argentina, Chile, and Colombia were better prepared to face the COVID-19 pandemic before it started. They allocated more public health resources as a percentage of GDP, spent less from out-of-pocket sources, had a higher GSHI, except for Colombia, and presented lower maternal mortality rates and diabetes prevalence as shown in Table 1. Chile, however, showed both the second highest percentage of out-of-pocket expenditures and the second highest diabetes prevalence after Mexico.

Brazil, Argentina, and Chile showed the three highest level of preparedness to face the pandemic measured with the GHSI and the highest percentage of their population over 65 years of age. Peru, except for having the lowest diabetes prevalence and percentage of elderly population, showed worse health system indicators.

Peru, Colombia, and Brazil are the three lowest income countries measured in US Purchasing Power Parity dollars (PPP) per capita, and have the highest percentage of people living in poverty or with a vulnerable job, except for Mexico (Table 1). Their distribution of income is more unequal measured with 
the GINI index, except for Chile which presented the second highest GINI after Brazil. Peru and Colombia presented the two highest percentages of their populations, nearly half with people living with a job very likely to be lost if the economic situation of their countries got worse. Argentina, Chile, and Peru showed the highest average years of schooling, achieving at least 9 years of formal education.

\section{Government policy responses}

Latin American health system's responses to the COVID-19 pandemic vary widely, both in timing and how stringently they have been implemented. Figure S1a (see Supplementary Material) shows trends of the most comprehensive government response index comprising the 17 indicators for each Latin American country from their declarations of health emergency around 12 March 2020 to the most recently available measurement of 23 September 2020.

Argentina and Peru began implementing stricter policies from 18 March 2020, while Colombia started them ten days later. All three governments maintained at least an $80 \%$ index through September, except for Colombia, that relaxed its policies in September 2020, lowering its index to 60\%. Chile adopted less stringent measures, up to $72 \%$, on average, in early April through the middle of June 2020 - then rising gradually to an average of $86 \%$ by the end of September 2020. Brazil began implementing stricter policies by early April 2020, up to $61 \%$, through July, then reached its highest percentage of 73 in early September 2020 , then stabilized at $71 \%$ by the end of that same month. Mexico implemented stricter policies until the end of March 2020 but reached only $63 \%$ on average between April and May 2020, then reduced its stringency to 55\% on average through the end of September 2020.

Figure S1b (see Supplementary Material 1) shows how strictly the three health government policies measured implementation of public information campaigns, testing policies, and contact tracing in each country. Similar to the overall government response index, Argentina, Peru, and Colombia started implementing such policies earlier than the other three countries, but only Argentina and Peru maintained percentages above 80 through the end of September 2020. Colombia relaxed its health mitigation polices in early September 2020 dropping its response level to $57 \%$, the lowest of the six countries analyzed. Chile implemented stricter polices by the end of March, rising its level of response to an average of 85 by the end of September 2020. Mexico began implementing its health policies with a level of response above $70 \%$ until the end of March and Brazil until early June. Brazil and Mexico relaxed their health policies through mid-August. They both then implemented stricter polices through the end of September 2020. Brazil reached $75 \%$ on average and Mexico only $65 \%$.

Figure S1c (see Supplementary Material 1) shows Chile and Mexico as the extremes. Although Chile started with a low level of economic response from early April through the middle of June 2020 with 38\%, it gradually increased its level from then to $75 \%$ through early August and then to $100 \%$ by the end of 
August 2020. Mexico, in contrast, did not adopt any economic policy response. Brazil provided some economic support, but it only reached a level of $50 \%$ on average throughout this same period. Argentina, Colombia, and Peru, however, have maintained a level of $75 \%$ since early April 2020, although Argentina and Peru started two weeks earlier.

\section{Mobility reduction in public spaces}

We explored the mitigation effects of these differential public policies by measuring the percentage of mobility reduction in public spaces starting on the date of declaration of a sanitary emergency to the most recent available measurement on 24 September 2020. Figure S2a (see Supplementary Material 2) shows heterogeneous mobility reductions in retail and recreational spaces such as restaurants, cafes, shopping centers, and cinemas.

Argentina and Peru showed the largest reductions, ranging from 60 to $90 \%$ during the period analyzed. Both presented decreasing trends, although Argentina showed a steadier one, achieving its highest reduction of 95\% in May 2020 and finishing with a $56 \%$ reduction by September 24, 2020, while Peru showed reductions ranging from 97 to 65 through June 2020, then 50 on average in July 2020, and again changing from nearly 90 to 45 by the end of the period analyzed.

Chile began with reductions of more than $60 \%$ until April 2020, then increased it to $75 \%$ until July 2020 and then again to $65 \%$ on average until September 2020. Colombia started with an $80 \%$ reduction through May 2020, but then gradually achieved lesser reductions, down to $40 \%$ by the end of the period analyzed. Mexico achieved its largest reduction of $80 \%$ in the middle of April 2020, but only gradually has reached 34\% reductions since August 2020. Brazil reached its highest reduction of $80 \%$ in early April 2020 but showed the lowest achievements from July 2020 until the end of the period analyzed with a $30 \%$ mobility reduction.

Figure S2b (see Supplementary Material 2) shows percent mobility reductions in public recreation areas such as parks, beaches, and squares. Argentina and Chile achieved the highest and most steady reductions, reaching on average $80 \%$ in Argentina and $70 \%$ in Chile. Peru achieved similar reductions, but with a less steady pattern. Colombia started with mobility reductions that reached $80 \%$ in early April 2020 , but by June only showed reductions of $40 \%$, then achieved higher reductions of $60 \%$ in July and August 2020 but reached reductions around $30 \%$ by the end of September 2020.

Mexico achieved its highest reduction of $60 \%$ in mid-April, gradually lowering this percentage to a thirty average by the end of the analyzed period. Brazil reached reductions of $60 \%$ on average in early April but since then has been achieving much lesser mobility reductions that range from $25 \%$ in mid-July to $3 \%$ by the end of August and then a smaller improvement of $20 \%$ by the end of September 2020.

Grocery and pharmacy shopping, which are the more necessary activities, showed lower percentage reductions in Figure S2c (see Supplementary Material 2). Peru and Chile achieved the highest reductions, although Peru showed ups and 
downs throughout the study period ranging from 45 to $95 \%$ reductions. Colombia achieved reductions of nearly $70 \%$ in mid-April 2020 to then reach lesser reductions ranging from $30 \%$ in mid-June 2020 to 16 by the end of the period analyzed. Mexico only reached a $29 \%$ reduction in mid-April, then lowered its reductions to nearly $10 \%$ on average by the end of September 2020 . In contrast to the other countries, Brazil reached minor reductions averaging 20\% through June 2020 and only mobility increases since then.

Less clear mobility reduction differentials were observed in transit stations such as subways, buses, and taxis, except for Peru and Brazil (Figure S2d). Peru reached the highest reductions throughout the analyzed period, nearly $90 \%$, except for June and July 2020, when it reached a $60 \%$ reduction on average. Brazil reached its highest reduction of $67 \%$ in mid-April but then showed a smaller reduction that ranged from $40 \%$ between May and June and then dropped to a $20 \%$ reduction through the end of September 2020.

Mobility reduction differentials in workplaces were less pronounced (Figure S2e). Peru and Chile presented the largest reductions on average, ranging from 70 to 30\%, followed by Mexico, Colombia, and Argentina with 37, 35, and 29 reductions, respectively. In contrast, Brazil only reduced its workplace mobility by $22 \%$.

\section{COVID-19 mortality rates}

Figure S3 (see Supplementary Material 2) shows the differential trends of weekly mortality rates in each Latin American country selected as of September 28, 2020. All countries, except Argentina, seemed to converge in similar mortality rates by the end of the period analyzed. Peru presented the highest weekly mortality rates throughout the analyzed period, reaching peaks of 15.5 and 16.1 per million population on July 26 and 16 August 16, 2020, respectively. Brazil and Mexico followed Peru with the second and third highest weekly mortality rates through June but then stabilized until the end of the period analyzed, at around 2.5 per million. Chile showed a less stable trend, growing until it reached its first highest weekly mortality rate of 14 June at 8.3 , to then decrease and grow again to that same highest rate of 8.2 a month later. Since then, it has shown a decreasing trend reaching 1.8, the lowest of the five countries, by the end of the period analyzed. Argentina and Colombia presented the lowest weekly mortality rates from March to the end of July but started a growing trend in early August 2020. Argentina reached the highest weekly mortality rate, 6.3 , by the end of the period analyzed and Colombia only 3.7 per million population.

\section{Discussion}

The results of the analysis showed that both timelier and more stringent implementation of the government policies to address the COVID-19 pandemic seem to be associated with higher mobility reductions, as other studies have shown $[1-3,7-12$, 21-25]. Argentina, Colombia, and Peru that started adopting these public health 
policies earlier and maintained higher degrees of stringency in their implementation, throughout most of the 6 months analyzed, showed higher mobility reductions. Mexico and Brazil, that implemented less strict mitigation policies and did so later than the other Latin American countries, presented the two lowest mobility reductions in all the public spaces analyzed.

The exploration also suggests that if public policies are relaxed, as most countries did when they 'reopened' their economies, mobility increases. Mexico did it first in early June, followed by Brazil in mid-June, while Argentina and Chile relaxed its policies in mid-July, Peru in early July, and Colombia did it until September 2020. If the measures adopted are more strictly implemented, as Chile did since July 2020, mobility may also be reduced.

Several factors may have influenced this differential effectiveness of the closure and restriction policies in reducing mobility in each Latin American country. One factor seems to depend on the degree of compliance of their respective populations $[8,9,11,12]$. People living in Argentina, Chile, and Peru were more compliant with these policies than those in Colombia, Brazil, and Mexico, as the higher mobility reductions showed. As other studies have shown, this higher compliance is related to their better socioeconomic conditions, including their lower levels of poverty, lower income inequality, lower percentages of their populations with living with vulnerable jobs, and their higher average years of schooling [8-10, 21-24, 26, 27].

Better communication from their governments $[9,11,27]$ and trust in their governments [28], as shown by other studies, are additional factors that may have influenced the differential mobility reductions and the mortality rates. Argentina, Chile, and Colombia implemented swifter and more strict public information campaigns, which in turn seemed to achieve higher mobility reductions [9, 11, 21, 22]. In contrast, Brazil and Mexico did not deliver an effective communication campaign. The presidents of Brazil and Mexico minimized the severity of the pandemic at its start. "You have to hug! It's okay!" insisted López Obrador, the president of Mexico, at one of his press conferences. Even on 22 March 2020, he invited Mexicans to eat at restaurants and enjoy in public spaces [29]. In March, Brazil's president commented at a press conference: "Obviously we have a moment of crisis, but it's a small crisis. From my point of view, the issue of coronavirus is much more fantasy and is not so much the case, as the great media propagates and spreads all over the world" [30].

Results also suggest that economic and social policies specifically implemented to reduce the impact of pandemic, together with the mitigation and health policies adopted, mainly by Chile and Argentina and to a lesser extent by Peru and Colombia [18], allowed people to comply with closure and containment policies due to income support and debt relief from their governments [21]. Argentina and Chile had stronger social protection systems in place before the pandemic started [31], including better health system indicators such as higher public expenditures as percentage of GDP and higher life expectancy at birth, as well as lower maternal mortality rates, but higher diabetes prevalence and percentage of elderly population [20].

In addition to its effects of mobility reduction, our analysis also suggests that more swiftly adopted and strictly designed and implemented government policies seem to be associated with lower mortality rates and potentially slower growing mortality rates as other studies have shown $[2,3,5,9,11,21-23]$. 
Responding to the outbreak more quickly, as Argentina did from 12 March 2020, at the time of the sanitary emergency declaration, along with maintaining stringency levels above $80 \%$ through the end of September 2020, including the most comprehensive contract tracing policy [18] may have contributed to keeping the lowest weekly death rates of the six countries throughout most of the period analyzed. Argentina's health system seemed better prepared given its highest percentage of public health expenditures (5.6\%), lowest out-of-pocket expenditures (15.8\%), highest GHSI (58.6), and its second lowest maternal mortality ratio (28.7), despite having the second highest percentage of its population older than 65 years of age (12\%). In terms of its socioeconomic situation, Argentina was both the richest and the least unequal country with the highest income per capita (19,820 US PPP), the lowest percentage of its population living in poverty $(10 \%)$ and extreme poverty $(1.4 \%)$ and smallest GINI coefficient (40.6). The growing weekly mortality rates presented in the last month of the period studied can be explained by an adjustment in the methodology of daily deaths reported [32].

The second lowest weekly mortality rates presented by Colombia, at least through August 2020, seem also to be associated with the prompt and strict government policies. Its higher weekly mortality rates presented by September 2020 seem to be associated with the relaxation of its closure and restriction public policies $[11,17,22]$. Colombia also conducted the most comprehensive testing policy of the six countries analyzed [18], testing anyone showing COVID-19 symptoms compared to the testing only those who both had symptoms and met specific criteria such as being admitted to a hospital, being high-risk care workers or returning from overseas. Other factors influencing this second lowest weekly mortality rates may be their second least unequal income distribution, including low out-of-pocket health expenditures $(20.2 \%)$, their stronger social protection system before the pandemic [20], and their economic support policies [21].

Brazil and Mexico presented higher weekly mortality rates than Argentina and Colombia throughout most of the study period, compared to Chile from late July 2020. This may be explained by less swift and strict implementation of mitigation policies, including the least comprehensive contact tracing policies, tracing only limited cases [9-11, 17, 22]. Mexico implemented the least restrictive policies on gatherings compared to Argentina and Peru that imposed restrictions on gatherings of 10 people or fewer [18]. These levels of responses, in turn, seem to lead to lower levels of compliance by the population in addition to the absence of an effective communication strategy from the government, as evidenced as well with the lower mobility reductions. Mexico's lower mortality rates than Chile and Peru, less populated countries, are also likely due to undercounting of deaths given the unreliability and incompleteness of their epidemiological surveillance systems as shown by recent studies $[22,33]$. Other factors include a more recent declaration by authorities of the Mexican Ministry of Health [34] and Mexico's highest diabetes prevalence, one of the main risk factors for COVID-19 death identified so far, along with having the second highest poverty level of the six countries analyzed [17].

Chile's trend of weekly mortality rates during the period analyzed grew gradually until early June 2020. Then it rose until it reached its first peak on 14 June 2020, when the Ministry of Health resigned over a controversy about the country's 
figures for COVID-19-related deaths [35], and its less restrictive policies, including limiting private gatherings to more than ten people. Chile also targeted social distancing measures by neighborhoods in Santiago, the nation's capital. A governance crisis that started 6 months before the COVID-19 pandemic may have undermined both government's authority and people's compliance during the first months of the pandemic. However, both socioeconomic living conditions of the population and its better health system indicators helped to better address the pandemic compared to other Latin American countries analyzed. With a new minister in place, Chile implemented stricter policies, including high rates of testing, but it only managed to lower its weekly mortality rates after the middle of July 2020 when it reached its second peak. Since then, its weekly mortality rates have decreased and have remained the lowest of the six countries throughout the rest of the period analyzed.

Despite its relatively prompt and strict government policy responses through June, Peru presented the highest weekly mortality rates on 26 July and 16 August 2020, when its government policies relaxed. Since then, it again became stricter and the population complied better maintaining a downward trend towards the end of the period studied. Peru's relatively high mortality weekly rates throughout most of this period are likely due to its having the worst health system conditions and socioeconomic living conditions for the population before the pandemic [16]. Peru's 88 maternal mortality ratio per hundred thousand population is the highest compared to the other countries, ranging from 64 in Brazil to 17 in Chile. Peru's coverage of basic sanitary services of $74 \%$ is the lowest compared to higher than $90 \%$ in the other five Latin American countries analyzed [36]. Peru had the lowest income per capita (13,810 US PPP) and the highest percentage of population living in poverty (45.1) and extreme poverty (16.3), as well as nearly $70 \%$ of its people working in the informal sector [37].

\section{Study limitations}

The data analysis was exploratory and should be interpreted as a preliminary assessment of the effectiveness of the public policies implemented by six Latin American countries. The Oxford indices allow for cross-national comparisons of government responses but are not comprehensive measures of all policy options. For example, the use of face masks has not been included yet [18]. However, these data provide insights about feasible public policies and how they may help mitigate the COVID19 pandemic in other settings with similar health system characteristics. Even though we considered both the socioeconomic conditions of their populations as well as the health system preparedness of each country, a quantitative multifactorial analysis is needed to better assess the effectiveness of the policies implemented. We recognize that data were aggregated at the national level while the outbreaks have been local, usually in densely populated cities in Latin America such as Buenos Aires, Bogotá, Mexico City, Rio de Janeiro, Santiago, and Lima, the capitals of the six countries analyzed. More research is needed at a more granular level to better understand what works best to mitigate the pandemic. Also, case studies should be conducted to analyze in more depth the policy processes of each country, including 
the political dimensions, to better understand and assess the consequences of decision making and implementation of COVID-19 mitigation policies.

\section{Policy lessons}

We draw five policy lessons from the above analysis of the six Latin American health systems. The first is that timely implementation of more strict mitigation and control public policies seem to be more effective for addressing the COVID-19 pandemic, as our analysis and other studies have shown.

Governments should also generate reliable, credible, and useful information, so that people can adopt the appropriate mitigation measures, such as washing hands frequently, using face masks, and staying at home. This is the second policy lesson. Currently, there is an excess of false or information of little use, which generates mistrust of the governments. In Brazil and Mexico, politicians have lost the trust of their people by contradicting their experts on basic facts about the pandemic, publishing implausible numbers on COVID-19 deaths, or underestimating its impact.

The third policy lesson is that using unreliable and incomplete information can lead to misguided policy making. Mexico, for example, where the government decided to gradually get back to 'normal' in June and started to loosen restrictions, still has not been able to mitigate the pandemic as well as the other Latin American countries, as of September 23, 2020; and new deaths continue to increase.

The fourth policy lesson is that people are more likely to comply with closure and social distance policies when they also receive some kind of income support to reduce their mobility needs, or if strong social protection systems were in place before the pandemic started.

Finally, health systems which maintain high levels of policy stringency and enforce restrictions together with income support and effective surveillance through testing policy and contact tracing will contribute more to mitigating the pandemic. Currently, this is particularly relevant, when incidence and mortality rates seem to be diminishing, and new waves of infections will rise if health systems let their guards down.

\section{Compliance with ethical standards}

Conflict of interest The Adolfo Martinez Valle states that there is no conflict of interest.

\section{References}

1. Chu DK, Akl EA, Duda S, Solo K, Yaacoub S, Schünemann HJ, et al. Physical distancing, face masks, and eye protection to prevent person-to-person transmission of SARS-CoV-2 and COVID-19: a systematic review and meta-analysis. Lancet. 2020. https://doi.org/10.1016/S0140 $-6736(20) 31142-9$. 
2. Hsiang S, Allen D, Annan-Phan S, Bell K, et al. The effect of large-scale anti-contagion policies on the COVID-19 pandemic. Nature. 2020. https://doi.org/10.1038/s41586-020-2404-8.

3. Organization for Economic Cooperation and Development (OECD). Flattening the covid-19 peak: Containment and mitigation policies, OECD Tackling COVI-19 Working Paper, Paris: 2020.

4. Li Q, Guan X, Wu P, et al. Early transmission dynamics in Wuhan, China, of novel coronavirus infected pneumonia. N Engl J Med. 2020. https://doi.org/10.1056/NEJMoa2001316.

5. Li L, Wong JY, Wu P, Bond HS, Lau EH, Sullivan SG, Cowling BJ. Heterogeneity in estimates of the impact of influenza on population mortality: a systematic review. Am J Epidemiol. 2018;187:378-88.

6. Anderson RM, Fraser F, et al. Epidemiology, transmission dynamics and control of SARS: the 2002-2003 epidemic. Philos Trans R Soc Ser B. 2004;359:1091-490.

7. Hollingsworth TD, Klinkenberg D, Heesterbeek H, Anderson RM. Mitigation strategies for pandemic influenza A: balancing conflicting policy objectives. PLoS Comput Biol. 2011;7:e1001076.

8. Miller MJ, Loaiza JR, Takyar A, Gilman RH. COVID-19 in Latin America: novel transmission dynamics for a global pandemic? PLoS Negl Trop Dis. 2020;14(5):e0008265. https://doi. org/10.1371/journal.pntd.0008265.

9. García P, Alarcón A, Bayer A, Buss P, Guerra G, et al. COVID-19 Response in Latin America. Am J Trop Med Hyg. 2020. https://doi.org/10.4269/ajmh.20-0765.

10. Jorge D, Rodrigues M, Silvaa MS, Cardim LL, da Silva NB, Silveira IH, Silva VA, Pereira FAC, Pinhoa TR, Andrade R, Ramo IP, Oliveira JF (2020) Assessing the nationwide impact of COVID-19 mitigation policies on the transmission rate of SARS-CoV-2 in Brazil. Unpublished submitted paper for peer review. See preprint at https://www.researchgate.net/publication/342519394.

11. Acosta LD. Capacidad de respuesta frente a la pandemia de COVID-19 en América Latina y el Caribe. Rev Panam Salud Publica. 2020;44:109. https://doi.org/10.26633/RPSP.2020.109.

12. De la Hoz-Restrepo F, Alvis-Zakzukb N, De la Hoz-Gomez JF, De la Hoz A, Gómez Del Corral L, Alvis-Guzmán N. Is Colombia an example of successful containment of the 2020 COVID19 pandemic? A critical analysis of the epidemiological data, March to July 2020. Int J Inf Dis. 2020;99:522-9. https://doi.org/10.1016/j.ijid.2020.08.017.

13. Greer SL, King EJ, da Fonseca EM, Peralta- SA. The comparative politics of COVID-19: The need to understand government responses. Global Public Health. 2020. https://doi.org/10.1080/17441 692.2020.1783340.

14. Bal R, de Graaff B, van de Bovenkamp H, Wallenburg I. Practicing Corona-Towards a research agenda of health policies. Health Policy. 2020;124:671-3. https://doi.org/10.1016/j.healt hpol.2020.05.010.

15. World Health Organization (WHO) 2007: Everybody business: strengthening health systems to improve health outcomes: WHO's framework for action.

16. Organización Panamericana de la Salud. Indicadores básicos 2019: tendencias de la salud en las Américas. Washington, DC: OPS; 2019.

17. Johns Hopkins Center for Health Security, Nuclear Threat Initiative, The Economist Intelligence Unit. Global Health Security Index 2019. https://www.ghsindex.org. Accessed 10 October 2020.

18. Banco Interamericano de Desarrollo. Del confinamiento a la reapertura: consideraciones estratégicas para el reinicio de las actividades en América Latina y el Caribe en el marco de la Covid-19 2020.

19. Hale T, Angrist N, Cameron-Blake E, Hallas L, Kira B, Majumdar S, Petherick A, Phillips T, Tatlow H, Webster S. Oxford COVID-19 government response tracker, Blavatnik School of Government. 2020, Available at https://www.bsg.ox.ac.uk/covidtracker.

20. Google LLC, Google COVID-19 Community Mobility Reports. https://www.google.com/covid19/ mobility. Accessed 3 July 2020.

21. Dong E, Du H, Gardner L. An interactive web-based dashboard to track COVID-19 in real time. Lancet Inf Dis. 2020;20(5):533-4. https://doi.org/10.1016/S1473-3099(20)30120-1.

22. Chertorivski S, Córdova JA, Frenk J, Juan M, Narro J, Soberón G. La gestión de la pandemia en México. Pensando en México, CDMX: Análisis preliminar y recomendaciones urgentes. Consejo Consultivo Ciudadano; 2020.

23. Kraemer MUG, et al. The effect of human mobility and control measures on the COVID-19 epidemic in China. Science. 2020. https://doi.org/10.1126/science.abb4218.

24. Alfano V, Ercolano S. The Efficacy of Lockdown Against COVID-19: A Cross-Country Panel Analysis. Appl Health Econ Health Policy. 2020;18:509-17. https://doi.org/10.1007/s40258-020-00596 -3 . 
25. Cardenas M and Martinez H. COVID-19 in Colombia. Impact and Policy Responses. Center for Global Development, July 2020.

26. Lewandowsky S, Ulrich KH, Ecker CM, Seifert NS, Cook J. Misinformation and Its Correction: continued influence and successful debiasing. Psychol Sci Public Interest J. 2012;13(3):106-31.

27. Martínez Villarreal D, Rojas Méndez AMY, Scartascini C. La economía del comportamiento puede ayudar a combatir el coronavirus. Washington, DC: Banco Interamericano de Desarrollo; 2020.

28. Elgar FJ, Stefaniak A, Wohl MJA. The trouble with trust: Time-series analysis of social capital, income inequality, and COVID-19 deaths in 84 countries. Soc Sci Med. 1982;16:113365.

29. https://www.eluniversal.com.mx/mundo/amlo-bolsonaro-y-otros-lideres-latinos-reprobados-ante-lapandemia. Accessed 7 July 2020.

30. https://www.eleconomista.com.mx/opinion/Los-populistas-AMLO-Bolsonaro-y-Trump-minimizanla-pandemia-20200316-0098.html. Accessed 7 July 2020.

31. Cecchini S, Filgueira F, Robles C. Social Protection Systems in Latin America. A Comparative Review. Economic Commission for Latin America and the Caribbean, Social Policy Series 202, Santiago: 2014.

32. https://www.covidstats.com.ar. Accessed 20 October 2020.

33. Romero M, Despeghel L. ¿Qué nos dicen las actas de defunción en la CD MX? Nexos 2020. Available at https://datos.nexos.com.mx/?p=1443. Accessed 9 July 2020.

34. https://www.coronavirus.gob.mx. Accesed 26 October 2020.

35. https://santiagotimes.cl/2020/06/13/pinera-replaces-health-minister-manalich-as-chiles-coronaviru s-tally-surpasses-167000/. Accessed 9 July 2020.

36. OECD/The World Bank. Panorama de la Salud: Latinoamérica y el Caribe 2020. Paris: OECD Publishing; 2020.

37. https://www.statista.com/statistics/1037216/informal-employment-share-latin-america-caribbeancountry/. Accesed 12 October 2020.

Publisher's Note Springer Nature remains neutral with regard to jurisdictional claims in published maps and institutional affiliations.

\section{Authors and Affiliation}

\section{Adolfo Martinez-Valle ${ }^{1}$ (D)}

Adolfo Martinez-Valle

adolfomartinezvalle@gmail.com

1 Head of Academic Unit, Health Policy and Population Research Center (CIPPS), Universidad Nacional Autónoma de México, CDMX, Ciudad Universitaria, Edificio CIPPS- Piso 2, 04510 Ciudad de México, Mexico 